\title{
The Effect of hand and foot massage on alleviating pain and anxiety of abdominal post-operative patients at a University Hospital: A randomized control trial
}

\author{
Naglaa F.A. Youssef ${ }^{1 *}(\mathrm{PhD}) \&$ Asmaa Diab A. Hassan ${ }^{2}(\mathrm{DNS})$ \\ ${ }^{1 \& 2}$ Lecturers at Medical-Surgical Nursing Department, Faculty of Nursing, Cairo University, Egypt
}

\begin{abstract}
:
Background: Controlling and relieving acute postoperative pain is one of the nurses' vital roles. Massage is an independent nursing intervention that can be applied to a patient who is in pain. This study aimed to evaluate the efficacy of hand and foot massage on alleviating pain and anxiety of patients who had abdominal surgery. Methods: A randomized control trial was conducted over a period of eight months for 60 women who had abdominal surgery. The participants were recruited from one of the big teaching hospitals in Cairo and quasirandomly allocated into the intervention or control group. The Numeric Rating Scale (NRS) and the State-Trait Anxiety Inventory (STAI-form Y-2) were used alongside a background/medical data sheet to collect the data. A foot and hand massage was performed for twenty-minutes for three days. Results: Although there was no significant difference between the massage and control groups' pain intensity at baseline (Day-1-pre test) $(p>0.05)$, the intervention group had a significantly higher decrease in pain intensity than the control group after applying a massage $(p \leq 0.000)$. Over $96 \%$ of the intervention group experienced moderate/severe anxiety, while 100\% of the control group experienced moderate/very severe anxiety at baseline with no significant difference $(p>0.05)$. After the three sessions of hand and foot massage, the intervention group showed a remarkably lower score of anxiety than the control group $(p=0.000)$. Conclusion: Hand and foot massage was significantly associated with the reduction of pain and anxiety intensity. It can therefore be used as a complementary method to reduce pain and anxiety in post-operative patients. A larger randomized study of males and females is required to generalize the findings.
\end{abstract}

Key words

Abdominal surgery, anxiety, foot massage, hand massage, postoperative pain

\section{Introduction}

Pain is one of the most common complaints of postoperative patients worldwide. Despite the drugs and anesthetic techniques available, the prevalence of post operative pain is still high [1]. For instance, about $41 \%$ of postoperative patients experienced moderate to severe pain, even though sedative drugs had been administered [2]. A large survey reported that of 300 patients, $86 \%$ experienced postoperative pain; of whom $75 \%$ had moderate/severe pain during the immediate postsurgical period. Although about $88 \%$ received pain medications $80 \%$ of them experienced adverse effects and $39 \%$ reported moderate/severe pain even after receiving it [3].

Anxiety is another unpleasant feeling that affects postoperative patients emotionally, psychologically and physically. Facing surgery may cause some normal anxiety-related behavior, but health care providers should monitor the patient's anxiety level to preclude the development of an anxiety disorder [2]. Anticipated postsurgical pain was the most prominent pre-surgical patient concern, and nearly half the patients reported a high anxiety level about anticipated pain before surgery [3].

Additionally, acute postoperative pain is often still ineffectively managed. The poor management of postoperative pain may increase the risk for patients to develop physiological responses to pain, which produce harmful effects on the body after surgery [4] or even develop chronic pain conditions in some vulnerable patients [5]. For instance, $74 \%$ of 300 postoperative patients were still experiencing high levels of pain after their discharge from hospital [3].

Varieties of pharmacological and non-pharmacological interventions to enhance optimal pain relief are available; however, patients' responses are individualized [6]. Pain medication is still the current gold standard treatment for acute postoperative pain relief [7]. However, there is an increasing global interest in applying alternative modalities and non-pharmacological approaches for pain and anxiety relief to overcome the adverse effects of medication, such as massage.

\subsection{Significance of the study}

Pain management is a complex yet essential function for health care providers. Effective pain management is crucial for individuals following surgery to provide comfort, prevent complications and boost recovery [8]. Massage is an independent nursing intervention that can be applied to patients in pain. Massage is 
easy to apply, cheap and no special equipment is needed. It could be embedded into daily nursing activities. However, a pertinent question is whether foot and hand massage relieves acute postoperative pain in patients after abdominal surgery. A critical analysis needs to determine its effect on relieving acute postoperative pain. Providing safe, effective pain management is a concern for all nurses caring for patients following surgery. Registered nurses at all levels of practice are primarily patient advocates who have a vital role in managing postoperative pain appropriately [8]. Massage therapy was found as essential element of the patients' healing experience after surgery [9]. Postoperative cardiac patients who received a foot massage were highly satisfied with the intervention and no barriers to implementing massage therapy were identified [9]. A growing body of literature supports the application of massage therapy in post operative open heart surgery patients [2;10]. However there is a shortage of knowledge regarding the effect of foot and hand massage on postoperative abdominal surgery.

The researchers observed in their clinical practice that postoperative pain and anxiety levels, especially in the days following surgery, were high; and the prescribed pain killers could not relieve the pain completely. Hence, it was worth to investigate the effect of hand and foot massage on relieving pain and anxiety symptoms in postoperative patients to establish evidence of its effectiveness and safety among these patients.

\section{Aim and Hypotheses}

This study aimed to examine the efficacy of hand and foot massage on alleviating pain and anxiety of patients who had abdominal surgery.

\section{These two hypotheses were tested:}

H1: The mean of pain score will be significantly lower in the study group who receive hand and foot massage than in the control group who receive traditional care only.

H2: The mean of anxiety score will be significantly lower in patients who receive massage therapy than in patients who do not receive it.

\subsection{Theoretical framework}

Tissue damage is the main cause of postoperative pain, since it induces the release of chemical mediators from the surgical wound [7]. Understanding the mechanism of massage and how it works on the body is essential to recognize how to acquire its benefits and achieve the end outcomes. Numerous theories explain how massage therapy affects the body. The "gate control theory" (GCT), developed by Melzack and Wall (1965), is the best to explain the mechanism of controlling pain. [11]. GCT proposes gated circuits, which are located in the superficial dorsal horn of the spinal cord, through which pain is generated and controlled. GCT suggests that pain impulses are regulated by gating mechanism along the central nervous system (CNS). They occur in the spinal cord, sites in the thalamus and limbic system. According to this theory pain impulses pass through the CNS when the gate is open, but not while it is closed. The gating mechanism either permits or inhibits the transmission of pain impulses. If large fibers (A-alpha \& A-beta) are stimulated, pain transmission is inhibited and the gate is closed. Large nerve fibers and dermatome layers contain tactile and pressure receptors, which can be stimulated by massage. These receptors consequently transfer the nerve impulses to the CNS. Therefore, GCT stipulates that massage provides stimulation which blocks or interrupts the pain signals sent to the brain. Massage can also stimulate the release of certain chemical substances in the body such as serotonin, which inhibits the transmission of noxious nerve signals to the brain, or endorphins, which make the body more relaxed $[11 ; 12]$.

\subsection{Design}

\section{Materials And Methods}

A randomized control trial design was utilized to accomplish this study.

\subsection{Population and Sample}

A sample of 60 patients who had general abdominal surgery was recruited over a period of eight months (August 2016 to March 2017). Patients were quasi-randomly allocated into a control group ( $\mathrm{n}=30$ ), and a massage group $(n=30)$ according to even or odd hospitalization admission code number.

\section{Inclusion criteria}

Patients who met the following inclusion criteria were invited to participate in this study:

- $\quad$ Adults $\geq 18$ years old

- Have the ability to answer the interviewer's questions

- Give informed consent and are hemodynamically stabilized

- Had abdominal surgery

- Received general anesthetics. 


\section{Exclusion criteria}

Patients were excluded from this study if they had any of the following:

- History of chronic pain

- Metastasis cancer, on narcotic medication

- Hand or foot amputation

- Wound on foot/hand, dementia, or psychiatric diagnosis

- Diagnosis of deep vein thrombosis, adrenal gland disorder, skin problems, dialysis fistula

- History of bone fracture in the past two months

- Previous history of message therapy

- Receiving warfarin

- Edema or ulcers in extremities

- Cardiac arrest during the past 72 hours

- Infectious diseases (skin, viral hepatitis, jaundice)

- History of second degree burn on more than $25 \%$ of the body surface

- Any problems related to blood vessels, diabetes

- Hypersensitivity to hand and foot massage

- Dependence on oxygenation apparatus

- Completely bedridden for a long time (risk of DVT).

\subsection{Setting}

The study was conducted in a general surgery wards in a teaching hospital in Cairo. This hospital is one of the largest public teaching hospitals in the Cairo region, where a great number of patients from different sociodemographic and economic backgrounds come to receive health care from different regions in Egypt.

\subsection{Measurements}

Socio-demographic and medical data sheet

The sheet had two parts, patients' characteristics and medical data, and it was used to collect the patients' characteristics such as age, gender, education and employment status. The medical data sheet was used to record the diagnosis, type of surgery, etc. The history of analgesic consumption was collected from the patient's medical records.

\section{Numeric Rating Scale (NRS) for pain}

The Pain Visual Analogue Scale (VAS) is the commonly used standardized pain measurement scale, which measures pain intensity. However, its test-retest reliability has been shown higher among literate $(r=0.94)$ than illiterate patients $(r=r=0.71)$ [13]. Numeric Rating Scale (NRS) is a segmented numeric version of the VAS, and it has a single 11-point numeric scale in which respondents select a number from 0 (no pain) to 10 (sever pain) to reflect the intensity of their pain. NRS has high test-retest reliability in both literate and illiterate patients $(\mathrm{r}=0.96 \& 0.95$, respectively) [13]. Therefore, NRS was used in this study to assess the pain intensity before and after each massage session. The patients were requested to select the number that represents their pain intensity. The overall score of the NRS ranges from $0-10$, and it can also describe pain intensity as no pain (0), mild pain (1-3), moderate pain (4-6), and severe pain (7-10).

\section{Spielberger's State-Trait Anxiety Inventory (STAI)}

The State-Trait Anxiety Inventory (STAI) was developed and used by Spielberger, Gorsuch, Lushene, Vagg, and Jacobs (1983) [14]. This scale has two inventories, 20 items for each: (1) State anxiety (STAI Form Y-1/SAI) measures the subjective experience of fear, nervousness and anxiety of current or recent times or scenes, as well as stress-state anxiety; (2) Trait anxiety (STAI Form Y-2/T-AI) measures the normal anxiety level. Only form Y-1/ STAI was used in this study to examine state anxiety, which ranged from 1-not at all; 2-sometimes; 3-moderately so and 4-very much so. By adding 20 items the total score was obtained. Phrases which showed a lack of anxiety were scored in reverse order. Scores of 20-42, 43-53, 54-64 and 65-75 were interpreted as mild, moderate, severe and very severe anxiety respectively, a higher score indicating a greater anxiety level. Y-1/ STAI has proofed to have a high reliability, alpha $=0.86-0.90$ [14]. The Arabic version, which has its validity and reliability well established among the Egyptian population was used, coefficient $>0.80$ [15]. Official permission to use this scale was obtained from www.mindarden.com.

\subsection{Intervention}

Swedish massage is the most commonly used type of massage therapy, which is often known as light or relaxation massage. Swedish massage therapy increases the circulation, which helps the body to be more relaxed and energized by relieving muscle tension and pain, thus increasing overall health and well-being. Swedish massage includes effleurage, petrissage, tapotement and friction techniques. Effleurage influences the superficial tissues and is used to apply the lubricant, spreading it over the surface. It aims to warm the surface 
layer of the tissue to create relaxation before applying other techniques. Petrissage is the kneading that follows effleurage. Tapotement (i.e. beating percussion) is a rhythmic short taps' application done with cupped hands, fingers, or the edge of the hand. Friction consists of deep and circular movements, which aim to rub the layers of tissue against each other in order to increase blood flow [16; 17].

\section{These steps were followed to apply the massage technique mentioned above [17]:}

1. Effleurage was used to spread the lubricant (olive oil) over the participant's hands and feet by massaging from the base of the fingers to the wrist or from the toes to the ankle.

2. Petrissage as a short, gentle and rapid movement was used to squeeze, roll or knead the hands, feet, fingers and toes.

3. Tapotement (i.e. beating or percussion) was used as short taps done with the fingers.

4. Friction was used to rub the layers of tissues against each other in order to increase blood flow.

The intervention group followed the routine ward care and in addition received 20 minutes of hand and foot massage, 5 minutes for each extremity, at a time for three days; while the control group followed the routine ward care, and received 20 minutes of rest time (to control for emotional reaction).

\subsection{Ethical considerations}

This study was conducted in accordance with the Helsinki Declaration. Official permission was obtained from the director of the hospital and surgical wards before data collection. Before obtaining the patients' consent, they were informed about the purpose and nature of the study. Their participation in the study was entirely voluntary and withdrawal from the study was permitted at any time with no effect on their care. The patient's anonymity and confidentiality was assured by coding the data with hidden identifying data such as a name.

\subsection{Pilot study}

A pilot study was conducted on five patients, who were then excluded from the main study sample. The pilot study aimed to: (i) estimate the required sample size (ii) calculate the time necessary to interview the patients, (iii) test the clarity and understandability of the questionnaires and (iv) examine the feasibility of the massage technique.

All questionnaires items were clear, understandable and no modification was required. Using an antiseptic solution to care for the feet before the massage was not acceptable to many patients. Therefore, it was decided to wash the feet by using only water and wearing gloves before demonstrating the massage. The results of the pilot study confirmed that the study was feasible.

\subsection{Procedure of data collection}

- Interview of the patient to explain the study in order to receive informed consent.

- Review of the patient's medical history to consider who meets the inclusion criteria.

- Check with the physician whether the patient has any of the contraindications to participate in the study.

- The patients were met over three consecutive days to do the following:

o First time (T-0) to complete the questionnaires (demographic data sheet, pain NRS and STAI), and first application of the hand and foot massage, which followed by recomplete the NRS.

- Second time (T-1) to re-complete the pain NRS questionnaire pre \& post application of the hand and foot massage and

- Third time (T-2) to re-complete the pain NRS pre \& post application of the hand and foot massage

The anxiety intensity using STAI was assessed only twice: at baseline [(T-0) pre massage] and posttest [(T-2) post massage].

The intervention group received 20 minutes of hand and foot massage per day for three consecutive days in the afternoon. Patients in the control group received routine hospital care only. The massage was initiated on the second day post-operatively to be dynamically stabilized. The assessment of baseline data and the massage were applied at least three hours after analgesics administration.

\subsection{Statistical data analysis}

Data were analyzed using SPSS statistical software version 20. Continuous data obtained before and after the massage for the three days were expressed as mean \pm standard deviation (SD). Categorical data were expressed in numbers and percent. The independent t-test was used to investigate the differences between two groups and the paired t-test was used to determine the differences pre and post massage application in each group. Changes in the pain and anxiety score were assessed using one way repeated measures analysis of variance (ANOVA). The Mann-Whitney test was used for variables that did not meet the parametric assumptions. The chi-square test was used to analyze the relationship between two variables in case of noncontinuous data. $\mathrm{P}$ value $<0.05$ was accepted as statistically significant. 


\section{Results}

The study results are presented in three sections: (1) Description of the study subjects' sociodemographic characteristics and related medical information, (2) Comparison of pain intensity at T-0, T-1 and $\mathrm{T}-2$ between control and intervention groups, and (3) Comparison of state anxiety intensity at T-0 and T-2 between control and intervention groups.

The mean age of the 60 participants was $40.37 \pm 10.34$ years, in the intervention group it was $38.07+11.39$ years, whereas in the control group it was $42.67+8.76$ years; however there was statistically no significant difference between both groups $(\mathrm{P}=0.085)$. TABLE 1 also shows that there is statistically no significant difference between the two groups in education, marital status, employment status and smoking habits $(\mathrm{P}>.05)$ which was calculated by chi-square test. However, there was a significant difference in the types of surgery in the two groups (Chi-square $=8.92, \mathrm{p}=0.01$ ). The control group had a higher prevalence of herniectomy than the intervention group (53.3\% vs. 23\%); while the intervention group had a higher prevalence of cancer colon, intestinal obstruction and stomach sleeve surgeries (see Fig. 1).

TABLE (1): Comparison Between Intervention And Control Groups' Characteristics ( $N=60)$.

\begin{tabular}{|c|c|c|c|c|c|}
\hline \multirow[t]{2}{*}{ Characteristics } & \multicolumn{2}{|c|}{ Intervention group $(n=30)$} & \multicolumn{2}{|c|}{ Control group $(n=30)$} & \multirow{2}{*}{$\begin{array}{c}\text { Pearson Chi- } \\
\text { square/t test } \\
\text { (p value) }\end{array}$} \\
\hline & $\mathbf{N}$ & $\%$ & $\mathbf{N}$ & $\%$ & \\
\hline Age (mean \pm SD) & \multicolumn{2}{|c|}{$\begin{array}{c}38.07+11.39 \\
(20-65)\end{array}$} & \multicolumn{2}{|c|}{$\begin{array}{c}42.67+8.76 \\
(22-55)\end{array}$} & 0.08 \\
\hline $\begin{array}{cc}\text { Gender } & \\
\bullet & \text { Female } \\
\end{array}$ & 30 & $100 \%$ & 30 & $100 \%$ & ----- \\
\hline $\begin{array}{cl}\text { Marital status } \\
\bullet & \text { Unmarried } \\
\bullet & \text { Married }\end{array}$ & $\begin{array}{c}5 \\
25\end{array}$ & $\begin{array}{l}16.7 \% \\
83.3 \%\end{array}$ & $\begin{array}{c}4 \\
26\end{array}$ & $\begin{array}{l}13.3 \% \\
86.7 \%\end{array}$ & $0.13(0.72)$ \\
\hline $\begin{array}{cl}\text { Education level } \\
\text { - } & \text { Uneducated } \\
\text { - } & \text { Can read \& write } \\
\text { - } & \text { Primary/preparatory school } \\
\text { - } & \text { Secondary/diploma school } \\
\text { - } & \text { Higher education }\end{array}$ & $\begin{array}{l}4 \\
7 \\
8 \\
8 \\
8 \\
3\end{array}$ & $\begin{array}{l}13.3 \% \\
23.3 \% \\
26.7 \% \\
26.7 \% \\
10.0 \% \\
\end{array}$ & $\begin{array}{c}1 \\
17 \\
4\end{array}$ & $\begin{array}{c}3.3 \% \\
56.7 \% \\
13.3 \% \\
\\
20.0 \% \\
6.7 \% \\
\end{array}$ & $7.78(0.10)$ \\
\hline $\begin{array}{cc}\text { Employment status } \\
\bullet \quad \text { Yes } \\
\bullet \quad \text { No } \\
\end{array}$ & $\begin{array}{l}13 \\
17\end{array}$ & $\begin{array}{l}43.3 \% \\
56.7 \% \\
\end{array}$ & $\begin{array}{l}19 \\
11\end{array}$ & $\begin{array}{l}63.3 \% \\
36.7 \%\end{array}$ & $2.41(0.12)$ \\
\hline
\end{tabular}

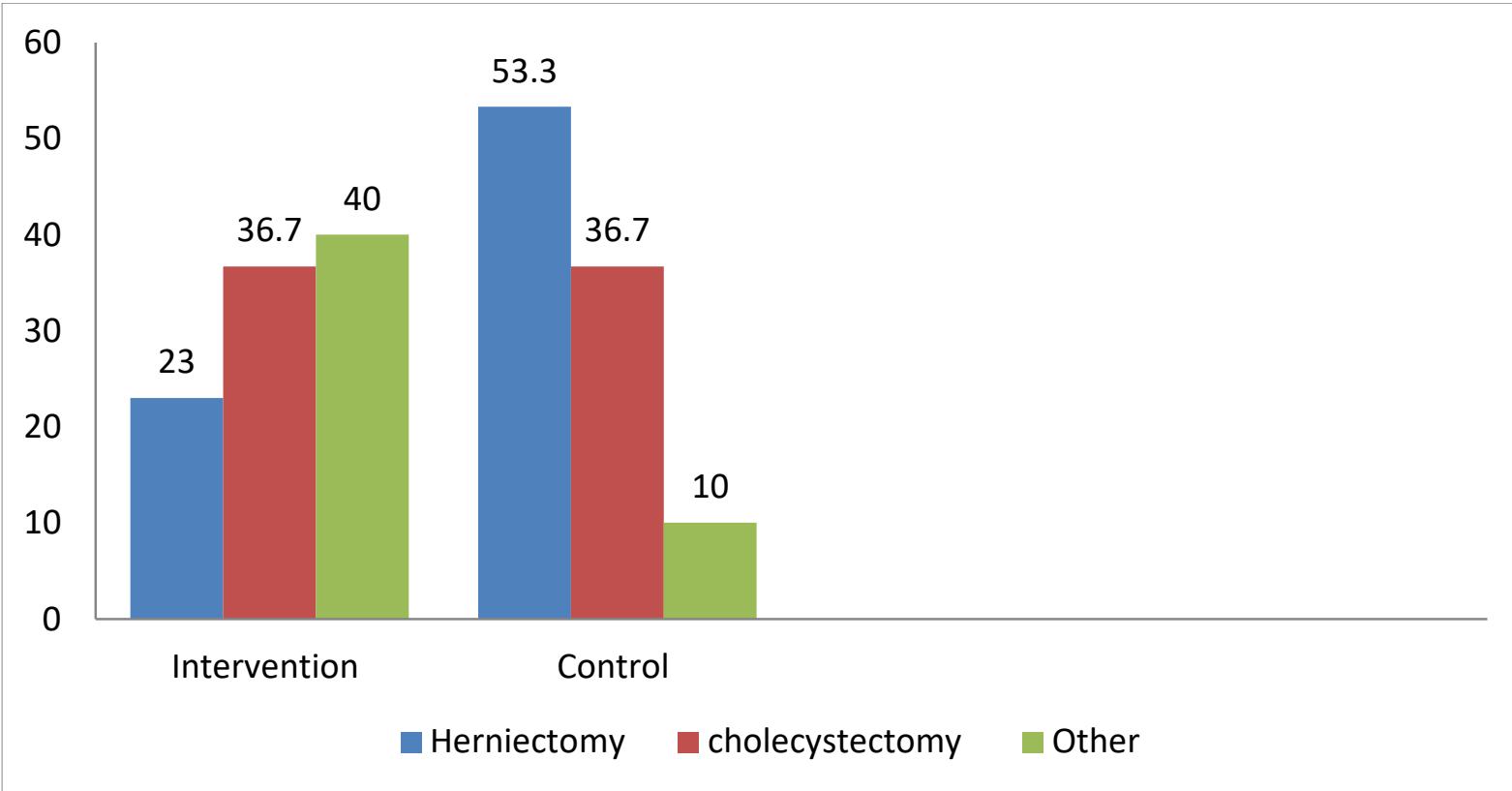

Figure (1): Distribution of Surgery Type of Intervention and Control Groups

TABLE 2 presents the one way repeated measure ANOVA which compares the pain intensity scores at T-0 (prior to the massage at day 2 after surgery), T-0 (following the massage at day 2 after surgery), T-1 (following the massage at day 3 after surgery) and T-2 (following the massage at day 4 after surgery). The 
results show that the mean score of pain intensity in the intervention group before and after the hand and foot massage had changed significantly $(\mathrm{p}=0.000)$. Also, the mean score of pain intensity in the control group before and after routine care had changed significantly $(\mathrm{p}=0.000)$. There was a significant effect of time on pain intensity in the intervention and control groups, where Wilks' Lambda $=0.10 \& 0.20$ respectively and multivariate partial eta squared $=0.90 \& 0.80$ respectively.

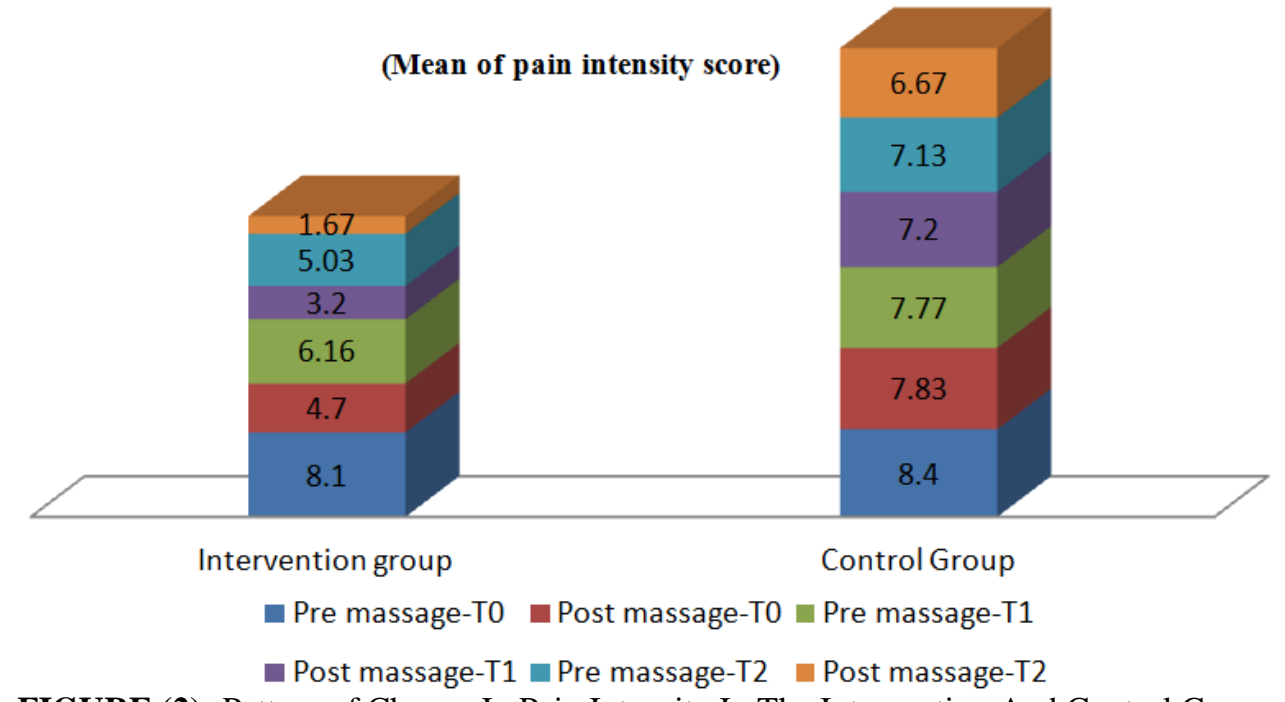

Fig. 2 illustrates the pattern of change in pain intensity at three measurement points (baseline, T-1 and T-2) in the intervention and control groups. Interestingly, although both groups had a significant decrease in pain intensity at the three measurement points $(\mathrm{p} \leq 0.05)$, the massage intervention group had a higher decrease of pain intensity than the control group, as the mean score illustrates.

Table (2): Comparison of Baseline And Post-Test Pain Scores In The Intervention And Control Groups Using Repeated Measures Anova

\begin{tabular}{|c|c|c|c|c|c|c|}
\hline \multirow{2}{*}{ Variable } & Pretest (T-0) & Posttest (T-0) & Posttest (T-1) & Posttest (T-2) & \multirow[t]{2}{*}{$\mathbf{F}$} & \multirow[t]{2}{*}{$\mathbf{p}$} \\
\hline & \multicolumn{4}{|c|}{ Mean \pm SD } & & \\
\hline $\begin{array}{l}\text { Pain (intervention group) } \\
\mathbf{n}=\mathbf{3 0}\end{array}$ & $8.10 \pm 1.18$ & $4.70 \pm 1.89$ & $3.20 \pm 1.80$ & $1.66 \pm 1.97$ & 75.95 & 0.000 \\
\hline Pain (control group) $n=30$ & $8.43 \pm .73$ & $7.83 \pm .74$ & $7.20 \pm .80$ & $6.66 \pm .88$ & 35.00 & 0.000 \\
\hline
\end{tabular}

TABLE 3 compares the intervention and control groups' pain intensity over time (for three days measurements). Although there is no significant difference between the two groups' pain intensity at baseline (Day-1-pre test) (p $=0.16)$, there is a significant difference between them at the other points of measurement $(\mathrm{p}=0.000)$.

TABLE (3): Comparison Of Intervention And Control Groups' Pain Intensity Over Time, Independent-T Test (Mann-Whitney Test)

\begin{tabular}{|c|c|c|c|c|}
\hline \multirow[t]{2}{*}{ Variable } & \multirow[t]{2}{*}{ Time of measure } & $\begin{array}{c}\text { Intervention group }(n= \\
\text { 30) }\end{array}$ & $\begin{array}{l}\text { Control group } \\
(n=30)\end{array}$ & \multirow[t]{2}{*}{ p. value } \\
\hline & & Mean rank & Mean rank & \\
\hline \multirow[t]{9}{*}{ Pain intensity } & \multicolumn{4}{|l|}{ Day-1 } \\
\hline & Pre massage & 27.47 & 33.53 & 0.160 \\
\hline & Post massage & 17.32 & 43.68 & 0.000 \\
\hline & \multicolumn{4}{|l|}{ Day-2 } \\
\hline & Pre massage & 20.10 & 40.90 & 0.000 \\
\hline & Post massage & 16.82 & 44.18 & 0.000 \\
\hline & \multicolumn{4}{|l|}{ Day-3 } \\
\hline & Pre massage & 19.22 & 41.78 & 0.000 \\
\hline & Post massage & 16.47 & 44.53 & 0.000 \\
\hline
\end{tabular}


Fig. 3 shows the change in anxiety intensity at two points of measurement (baseline and T-2) in the intervention and control groups. Interestingly, although both groups have a significant decrease in anxiety intensity between pre and post massage, the massage intervention group has a greater decrease of anxiety intensity than the control group.

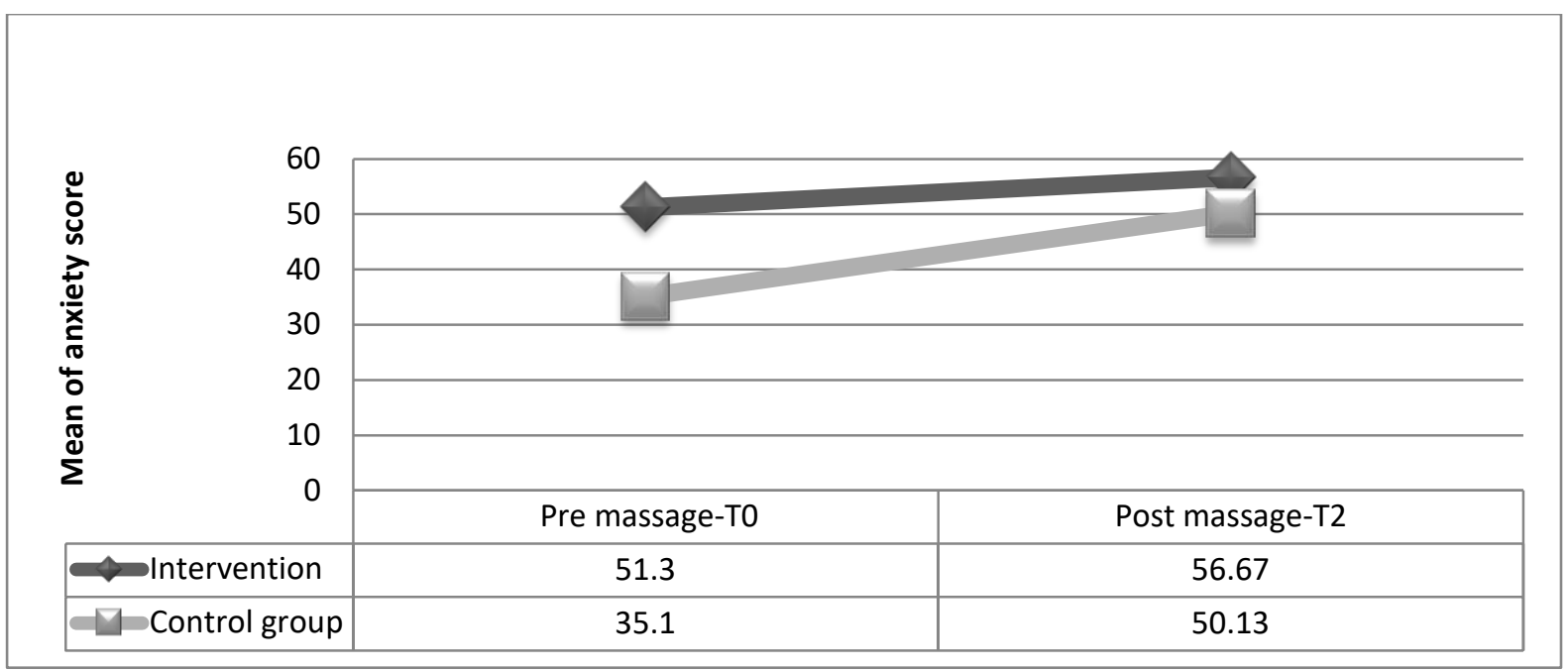

FIGURE (3): Change In Anxiety Intensity In The Intervention And Control Groups

TABLE 4 shows the distribution of patients according to their anxiety level at T-0 and T-2. The results of the STAI scale reveal that $96.7 \%$ of the intervention group experienced moderate to severe anxiety, while $100 \%$ of the control group experienced moderate to very severe anxiety at time 0 . However, there is no significant difference between the massage and control groups at T-0 ( $\mathrm{p}=0.51)$. At $\mathrm{T}-2$, after the three massage sessions, the massage group has a remarkably lower anxiety score than the control group $(\mathrm{p}=0.000)$.

TABLE (4): Comparison Of The Intervention And Control Groups' State Anxiety Over Time, Independent-T

\begin{tabular}{|c|c|c|c|c|c|c|}
\hline \multirow[t]{2}{*}{ Variable } & \multirow[t]{2}{*}{$\begin{array}{l}\text { Time of } \\
\text { measure }\end{array}$} & \multicolumn{2}{|c|}{$\begin{array}{l}\text { Intervention group } \\
(\mathrm{n}=\mathbf{3 0})\end{array}$} & \multicolumn{2}{|c|}{$\begin{array}{c}\text { Control group } \\
(\mathbf{n}=\mathbf{3 0})\end{array}$} & \multirow[t]{2}{*}{$\begin{array}{l}\text { Independent t-test } \\
\text { (P. value) }\end{array}$} \\
\hline & & Anxiety level \% & $\begin{array}{c}\text { Mean } \\
\text { rank }\end{array}$ & Anxiety level \% & $\begin{array}{c}\text { Mean } \\
\text { rank }\end{array}$ & \\
\hline \multirow[t]{2}{*}{$\begin{array}{l}\text { Anxiety } \\
\text { intensity }\end{array}$} & T-0 baseline & $\begin{array}{l}\text { Mild = } 3.3 \\
\text { Moderate = 50.0 } \\
\text { Severe }=46.7\end{array}$ & 26.12 & $\begin{array}{l}\text { Moderate }=23.3 \\
\text { Severe }=73.3 \\
\text { Very severe }=3.3\end{array}$ & 34.88 & 0.51 \\
\hline & $\mathrm{T}-22^{\text {nd }}$ measure & $\begin{array}{l}\text { Mild = 83.3 } \\
\text { Moderate = } 13.3 \\
\text { Severe = } 3.3\end{array}$ & 19.53 & $\begin{array}{l}\text { Mild }=30.0 \\
\text { Moderate }=30.0 \\
\text { Severe }=36.7 \\
\text { Very severe }=3.3\end{array}$ & 41.47 & 0.000 \\
\hline
\end{tabular}

\section{Discussion}

Pain is one of the commonly experienced symptoms by patients with acute and chronic conditions [7]. Nurses have a crucial role to control postoperative pain. The two methods most commonly used for pain control are pharmacologic and non-pharmacologic. However, the pharmacological approach may not entirely relieve all aspects of postoperative pain. Therefore, non-pharmacological methods such as massage may potentially relieve postoperative pain [7]. A review conducted by [7] concluded that foot massage as one of the complementary therapies proved to decrease the pain level in patients with acute postoperative pain. Anxiety is another related unpleasant feeling that affects postoperative patients emotionally, psychologically and physically. It is characterized by a feeling of threat that could be real or unreal [2]. Therefore, our study aimed to investigate the effects of hand and foot massage on relieving pain and anxiety symptoms in postoperative patients. The study's findings are discussed in three sections: (1) Study subjects' socio-demographic characteristics and related medical information, (2) Comparison of pain intensity at three time points in the control and intervention groups, and (3) Comparison of state anxiety intensity at three time points in the control and intervention groups.

\section{(1) Study subjects' socio-demographic characteristics and related medical information}

Sixty patients with abdominal surgery participated in this study. They were quasi-randomly distributed into an intervention and control group. There was no significant difference between the two groups in terms of their socio-demographic and medical data, although the type of surgery was significantly different. However, the baseline of pain and anxiety intensity was the same in the two groups. 
Only women participated in the current study, as gender as an extraneous variable has been found related to the response of pain management. Gender is an important factor in the response not only to postoperative pain but also to anesthetics and pain management. For instance, it has been reported that males wake up more slowly than women after general anesthesia and that they have fewer postoperative gastrointestinal disturbances [18]. The literature supports that males and females differ in their response to pain, as higher pain sensitivity is commonly observed in females. Females' sexual hormones seem to be linked to these differences [18; 19]; however, further studies are needed to explain the underlying mechanisms, including the contribution of hormonal and genetic factors [19]. The response to pharmacological and non-pharmacological pain management in males and females is still under investigation. Women reported more pain in more bodily areas with greater frequency and for a longer duration than men [20]. Our study sample was all females, which may also explain why the majority in our study were non-smokers.

Pain medication is considered a confounding variable because each medicine has different pharmacokinetic and pharmacodynamic properties. According to previous research, these drugs give different responses to patients' pain; research studies need to control the effect of pain medication, for example by having similar pain medication given to each patient [7]. In the current study, all participating patients routinely took non steroidal anti-inflammatory (NSAI) pain medication which provided the same analgesic effect. Also to control any pain medications effect; the assessment of baseline data and the massage were applied at least three hours after analgesics administration.

\section{(2) Comparison of pain intensity at three points in time in the control and intervention groups}

In relation to pain intensity, the current study's results show that the mean score of pain intensity significantly decreased in the intervention group who received hand and foot massage in comparison to the control group who received only routine care. This finding is consistent with previous studies, which support our results that pain severity significantly decreased in the intervention group compared to the control group. All had abdominal surgery, but the intervention groups had 20 minutes of hand and foot massage (effleurage and kneading) on three days [21]. In postoperative patients, 20-minutes of foot and hand massage significantly reduced both pain intensity and pain distress resulting from the wound on the first postoperative day [22]. Interestingly, in women who had a hysterectomy there was a significant reduction in pain in the experimental group following a hand and foot massage compared to the control group [23]. Additionally, foot and hand massage was effective in decreasing postoperative pain in open heart surgery patients [24]. This indicates that whatever the surgery type, massage is effective in decreasing postoperative pain.

It is essential to highlight the important findings in the current study are congruent with previous studies [21]. As our results show, hand and foot massage could help to decrease pain intensity and gave some amount of comfort to the patients. A review study that aimed to identify the effect of foot massage on relieving acute postoperative pain recommended that pharmacologic and non-pharmacologic management be used together to relieve pain. Using a pharmacologic approach alone may not fully relieve all aspects of acute postoperative pain [7].

Current evidence supports that massage has promising safe effects for the alleviation of pain, tension and anxiety. Bauer and colleagues [9] investigated the effect of foot massage versus relaxation on postoperative back and shoulder pain, anxiety and tension in a randomized group of cardiac surgery patients. Their results show that patients receiving massage therapy had a significant decrease in pain, anxiety and tension. Additionally, massage versus vibration therapy was tested [25] for short-term postsurgical pain, negative affect and physiologic stress reactivity on a randomized sample of women who underwent an abdominal laparotomy for the removal of suspected cancerous lesions. The results showed that on the day of surgery, massage was more effective than the usual care (UC) for affective and sensory pain, and better than vibration therapy for affective pain. On postoperative day 2, massage was more effective than UC for distress, and better than vibration therapy for sensory pain. However, after controlling for multiple comparisons and multiple outcomes, no significant differences were found [25]. Several studies showed the efficacy of foot massage to decrease acute postoperative pain $[26 ; 22]$. Our study findings support the efficacy of massage on relieving pain, where skin contact by massage is effective in relieving pain and anxiety.

\section{(3) Comparison of state anxiety intensity at two points in time in the control and intervention groups}

Our study findings show that there was no significant difference between the intervention and control groups regarding anxiety intensity before the massage. However, the anxiety level was significantly decreased in the intervention group, who received hand and foot massage along with routine care, as compared to the control group, who received only routine care. This difference indicates the positive effect of hand and foot massage on decreasing the anxiety intensity after surgery. Our findings are similar to previous studies that examined the effect of 20 minutes massage therapy on pain, anxiety and tension in cardiac surgical patients. The anxiety score significantly decreased in those patients who received massage alongside standard care [9; 27]. A 
previous study also showed that those patients who received massage therapy were highly satisfied with the intervention and no major barriers to its implementation were observed [27]. These results suggest that massage therapy is an important, safe and effective non-pharmacological intervention that should be considered for inclusion in the management of postoperative recovery of surgical patients [10].

A recent review [10] of patients in the intensive care unit concluded that applying massage therapy as a non-pharmacological method at least once a day for $20 \mathrm{~min}$ in the early days after cardiac surgery confirmed a remarkable reduction in the pain and anxiety score. However, large and high quality randomized control trials are needed to examine further important outcomes in the recovery of surgical patients.

\section{Conclusion}

This study's findings concluded that pain and anxiety are commonly experienced symptoms in the majority of postoperative patients. Hand and foot massage as a non-pharmacological nursing intervention showed a significant impact on decreasing these symptoms. An increase in nurses' awareness about the importance of applying massage after surgery can relieve the feelings of pain and anxiety in many of these patients. Also, nurses have a vital role in enhancing the knowledge and skills of post-operative patients and their caregivers through teaching sessions of how to use massage to relieve pain and anxiety after surgery.

\section{Implications And Recommendations}

Using hand and foot massage in surgical patients has notable effects on decreasing pain intensity and anxiety levels post-operatively. With decreasing pain intensity and anxiety levels patient complaints will also decrease and their satisfaction with the delivered healthcare will be increased. At the same time, post-operative complications associated with the increased intensity of pain and anxiety will decrease. Based on this study's findings we recommend the following:

1. Patients undergoing general abdominal surgery should be provided with a simple and applicable strategy to control pain and anxiety.

2. The assessment of preoperative anxiety should be recorded in the patient's medical records in order to provide a baseline for comparison with post-operative anxiety levels.

3. Healthcare providers, especially nurses, should frequently assess the patient's pain and teach the patient non-pharmacological strategies, such as massage, to relieve it.

4. A systematic pain assessment can be integrated into the daily routine of nurses. Frequent assessment of pain has been found to be useful information that helps healthcare providers in making appropriate decisions on managing pain [6].

5. The development of an educational program to improve nurses' knowledge of pain and how to manage it using non-pharmacological interventions is required.

\section{Limitations}

Further studies are required to assess patients' satisfaction with massage therapy and its association with potential post-operative complications such as wound healing and length of hospital stay. There is a need to replicate this study on a larger randomized trial on adult males and females to achieve more generalizable results.

\section{Acknowledgements}

The authors would like to express their gratitude to all the patients who accepted to participate in this study. We also extend our thanks to all respectful medical and nursing staff for helping us in conducting this study.

\section{Conflict of Interest}

The authors declare no conflict of interest.

\section{References}

[1] Hoogervorst-Schilp J, van Boekel RL, de Blok C, Steegers MA, Spreeuwenberg P, Wagner C. Postoperative pain assessment in hospitalised patients: National survey and secondary data analysis. International Journal of Nursing Studies. 2016 Nov 30;63:12431.

[2] Kaur S, Lobo DJ, Latha T. Role of foot and hand massage on the anxiety for post operative open heart surgery patients: A Randomized Control Trial. International Journal of Nursing Education. 2013 Jul 1;5(2):205.

[3] Gan TJ, Habib AS, Miller TE, White W, Apfelbaum JL. Incidence, patient satisfaction, and perceptions of post-surgical pain: Results from a US national survey. Current Medical Research and Opinion. 2014 Jan 1;30(1):149-60.

[4] Asadizaker M, Fathizadeh A, Haidari A, Goharpai S, Fayzi S. The effect of foot and hand massage on postoperative cardiac surgery pain. International Journal of Nursing and Midwifery. 2011 Oct 30;3(10):165-9.

[5] Deumens R, Steyaert A, Forget P, Schubert M, Lavand'homme P, Hermans E, De Kock M. Prevention of chronic postoperative pain: Cellular, molecular, and clinical insights for mechanism-based treatment approaches. Progress in neurobiology. 2013 May $31 ; 104: 1-37$ 
[6] Van Dijk JF, Vervoort SC, Van Wijck AJ, Kalkman CJ, Schuurmans MJ. Postoperative patients' perspectives on rating pain: A qualitative study. International journal of nursing studies. 2016 Jan 31;53:260-9.

[7] Chanif C, Petpichetchian W, Chongchareon W. Does foot massage relieve acute postoperative pain? A literature review. Nurse Media Journal of Nursing. 2013 Jan 31;3(1):483-97.

[8] Ward CW. A decision tree model for postoperative pain management. Urologic Nursing. 2015 Sep 1;35(5):251-7.

[9] Bauer BA, Cutshall SM, Wentworth LJ, Engen D, Messner PK, Wood CM, Brekke KM, Kelly RF, Sundt TM. Effect of massage therapy on pain, anxiety, and tension after cardiac surgery: a randomized study. Complementary Therapies in Clinical Practice. 2010 May 31;16(2):70-5

[10] Miozzo, A.P., Stein, C., Bozzetto, C.B. and Plentz, R.D.M., 2016. Massage therapy reduces pain and anxiety after cardiac surgery: A systematic review and meta-analysis of randomized clinical trials. Clinical Trials and Regulatory Science in Cardiology, 23, pp.18 .

[11] Melzack R, Wall PD. Pain mechanisms: A new theory Science, (1965), 150: 971-979

[12] Moyer, CA., Rounds, J. and Hannum, JW., 2004. A meta-analysis of massage therapy research. Psychological Bulletin, 130(1), pp.3-18. http://dx.doi.org/10.1037/0033-2909.130.1.3

[13] Hawker GA, Mian S, Kendzerska T, French M. Measures of adult pain: Visual Analog Scale for pain (VAS pain), Numeric Rating Scale for pain (NRS pain), McGill Pain Questionnaire (MPQ), Short-Form McGill Pain Questionnaire (SF-MPQ), Chronic Pain Grade Scale (CPGS), Short Form-36 Bodily Pain Scale (SF-36 BPS), and Measure Of Intermittent And Constant Osteoarthritis Pain (ICOAP). Arthritis Care \& Research. 2011 Nov 1;63(S11):S240-52.

[14] Spielberger, CD. Gorsuch, RL, Lushene, R, Vagg, PR, Jacobs, G., Manual for the state-trait anxiety inventory (form Y1). 1983. Palo Alto, CA: Consulting Psychologists.

[15] Abdel-Khalek, A.M., 1989. The development and validation of an Arabic form of the STAI: Egyptian results. Personality and Individual Differences, 10(3), pp.277-285.

[16] Stone, V., 2010. The world's best massage techniques the complete illustrated guide: Innovative bodywork practices from around the globe for pleasure, relaxation, and pain relief. Fair Winds Press.

[17] Salvo, S.G., 2015. Massage therapy: Principles and practice. Elsevier Health Sciences.

[18] Keogh E, McCracken LM, Eccleston C. Do men and women differ in their response to interdisciplinary chronic pain management?. Pain. 2005 Mar 31;114(1):37-46.

[19] Bartley EJ, Fillingim RB. Sex differences in pain: a brief review of clinical and experimental findings. British Journal of Anaesthesia. 2013 Jul 1;111(1):52-8.

[20] Campesi I, Fois M, Franconi F. Sex and gender aspects in anesthetics and pain medication. In sex and gender differences in pharmacology 2013 (pp. 265-278). Springer Berlin Heidelberg.

[21] Joy C, Arora S, Tamang EL. A Study to assess the effectiveness of foot massage on pain among patients after abdominal surgery in a selected hospital of Delhi. International Journal of Nursing Education. 2014;6(2):112-6.

[22] Wang HL, Keck JF. Foot and hand massage as an intervention for postoperative pain. Pain Management Nursing. 2004 Jun 30;5(2):59-65.

[23] Chithra PN, D'Almeida S. Effectiveness of hand and foot massage on pain among women who have undergone abdominal hysterectomy in selected hospitals at Mangalore. Asian Journal of Nursing Education and Research. 2014 Jul 1;4(3):337.

[24] Kaur S, Lobo DJ, Latha T. Effectiveness of hand-foot massage on the post operative pain among open heart surgery patients: A randomised control trial. In Worldwide Nursing Conference (WNC) 2014 Jul 21.

[25] Taylor AG, Galper DI, Taylor P, Rice LW, Andersen W, Irvin W, Wang XQ, Harrell Jr FE. Effects of adjunctive Swedish massage and vibration therapy on short-term postoperative outcomes: A randomized, controlled trial. The Journal of Alternative \& Complementary Medicine. 2003 Feb 1;9(1):77-89.

[26] Kim JH, Park KS. The effect of foot massage on post operative pain in patients following abdominal surgery. Journal of Korean Academy of Adult Nursing. 2002 Mar 1;14(1):34-43.

[27] Cutshall SM, Wentworth LJ, Engen D, Sundt TM, Kelly RF, Bauer BA. Effect of massage therapy on pain, anxiety, and tension in cardiac surgical patients: A pilot study. Complementary Therapies in Clinical Practice. 2010 May 31;16(2):92-5. 